Acta Poetica $26(1-2)$

PRIMAVERA-OTOÑO

2005

\title{
Hacia una tipología del son en México
}

\author{
Rosa Virginia Sánchez García
}

Debido a la naturaleza autónoma de las coplas y a su compleja relación con la música, no ha sido emprendido, hasta la fecha, un estudio de la literatura de este género dentro del contexto que le da sentido y del cual es inseparable: la melodía. Aquí se propone mostrar un estudio de las coplas dentro del contexto de los sones, considerando los rasgos literarios particulares de las diversas variantes regionales de éstos.

The purpose of this paper is to analyze coplas in the musical context of the sones in which they are sung. To understand coplas' lyric reality, their transmission and reception among a specific group of people have to be considered. This study will also need to consider the particular literary features of different regional version of the son. This approach will improve our knowledge of this important lyric genre of popular culture. 
Acta Poetica $26(1-2)$

PRIMAVERA-OTOÑO

2005

Rosa Virginia Sánchez García

Centro Nacional de Investigación, Documentación

e Información Musical-INBA

\section{Hacia una tipología del son en México}

Aunque con el término de son se suele denominar una gran cantidad de manifestaciones musicales diferentes - al parecer, costumbre derivada del uso corriente con que este vocablo se ha aplicado indistintamente desde siempre-, este estudio únicamente hace referencia al género lírico-coreográfico de carácter festivo que en la actualidad es cultivado, principalmente, por la población mestiza de diversas zonas localizadas a lo largo de las costas mexicanas y regiones aledañas en las estribaciones de las Sierra Madre Oriental y Occidental.

Una serie de rasgos literarios, musicales y coreográficos comunes - esbozados desde hace tiempo por diferentes autores como Jas Reuter (1981, 154-163), Thomas Stanford (1984, 14-32), y el mismo Vicente T. Mendoza (1984, 65-71) han permitido afiliar diversas expresiones musicales bajo el término de son. A partir de observaciones que consideran sólo ciertos aspectos (dotación instrumental y modos de interpretación, principalmente) se ha determinado que son seis las principales variantes regionales de este género. Por el lado del Golfo de México: los sones jarochos y los sones huastecos: los primeros, cultivados en las regiones de Sotavento, Los Tuxtlas y la 
zona del Istmo del estado de Veracruz, así como en una pequeña porción de Oaxaca, y los segundos, en la región de donde toman su nombre. Por el lado del Pacífico: los sones tixtlecos, de la montaña guerrerense; los sones calentanos, propios de las diversas poblaciones asentadas en las cercanías del río Balsas en Michoacán y Guerrero; los sones planecos o de "arpa grande" que corresponden a la zona que se ubica en la depresión del río Tepalcatepec, en Michoacán, y los sones jaliscienses, también llamados "de mariachi”, que abarcan parte de los estados de Nayarit y de Colima, además del propio Jalisco. Los anteriores, además, están emparentados con otros muy similares como los sones istmeños de Oaxaca, las chilenas, los gustos de la Costa Chica y las jaranas yucatecas.

Cada una de estas expresiones locales denota singularidades importantes, no sólo en cuanto al estilo de interpretación y la dotación instrumental, sino también en relación al repertorio, el ritmo, el tipo de estrofas cantadas, la estructura literario-musical, así como las principales tonalidades, tipos de afinación y círculos armónicos utilizados, diferencias en las cuales se ha puesto poca atención. ${ }^{1}$ En estas líneas trataré de mostrar un panorama comparativo de tales diferencias, concentrándome en el aspecto literario.

\section{La lírica cantada en los sones mexicanos}

Una de las principales características del son consiste en que la poesía cantada en éste se compone siempre de coplas, es

\footnotetext{
${ }^{1}$ A pesar de las aportaciones hechas por los autores mencionados, es importante notar que ellos mismos cayeron en generalizaciones que no son, en lo absoluto, aplicables a todos los ejemplos musicales considerados sones, y ni siquiera a todas las variantes regionales de este género. Esto sucede, por ejemplo, cuando se dice que el son es un género profano que "jamás interviene en ceremonias religiosas" (Reuter 1981, 156), o que el baile es de parejas y "expresa siempre el coqueteo entre varón y mujer" (Reuter 1981, 157), o que "la forma musical general es en estrofas con un estribillo y una introducción instrumental..." (Stanford 1984, 10), o que el son es esencialmente imitativo, lo mismo en la voz que en los efectos instrumentales y coreográficos (Mendoza 1984, 66).
} 
decir, breves poemas que encierran dentro de sí una idea completa, terminada, por lo que no requieren de la ilación con otras coplas para tener sentido. ${ }^{2}$ El carácter autónomo propio de las coplas es lo que permite que éstas se asocien de manera aleatoria en series que suelen variar de una interpretación a otra; es decir, que del repertorio total — mayor o menor- de coplas que pueden cantarse en un son particular, los trovadores hacen, en cada ejecución musical, una selección a su entero gusto y sólo cantan algunas de ellas, por lo que las distintas coplas no tienen un lugar específico dentro de la composición. Como consecuencia de lo anterior, la letra de un mismo ejemplo musical suele ser diferente en cada interpretación (en algunos casos, resulta prácticamente imposible encontrar dos versiones iguales desde el punto de vista del texto). Esto se puede ilustrar con las siguientes tres versiones del son jarocho El buscapiés: ${ }^{3}$

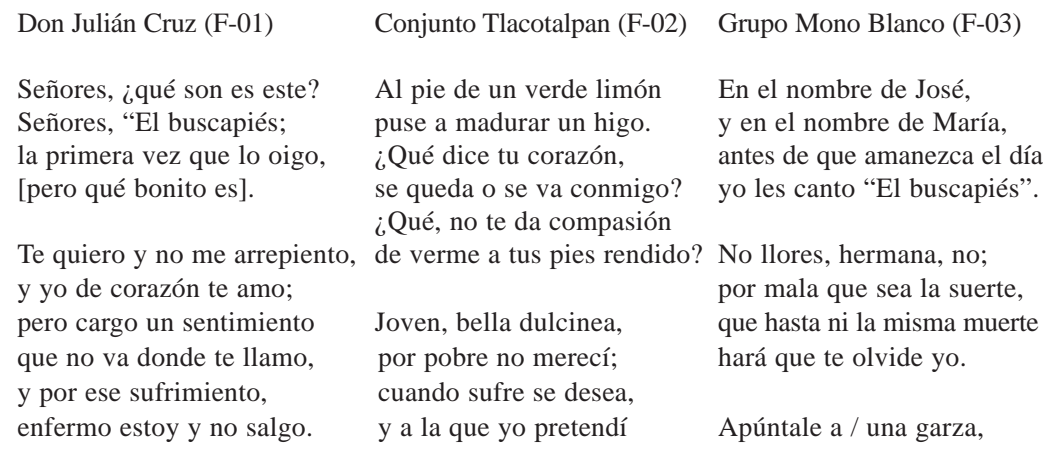

\footnotetext{
${ }^{2}$ Algunos autores, consideran necesario hacer explícita la distinción que existe entre las coplas y las estrofas. Jas Reuter, por ejemplo, decide aplicar el término de estrofas para aquellas que forman parte de una unidad mayor, y denomina coplas a las que para tener sentido, se bastan a sí mismas (Reuter 1981, 158). Mercedes Díaz Roig, por su parte, refiriéndose a la música tradicional de España, también hace la distinción entre coplas sueltas (aquellas que se pueden cantar solas) y estrofas, a las que define como "aquellas coplas que forman parte de una determinada canción y que no se pueden cantar aisladas, por estar unidas conceptualmente a las otras coplas de la canción” (Díaz Roig 1976, 11-12).

${ }^{3}$ En estos ejemplos se omiten las repeticiones de versos que corresponden a la interpretación musical.
} 


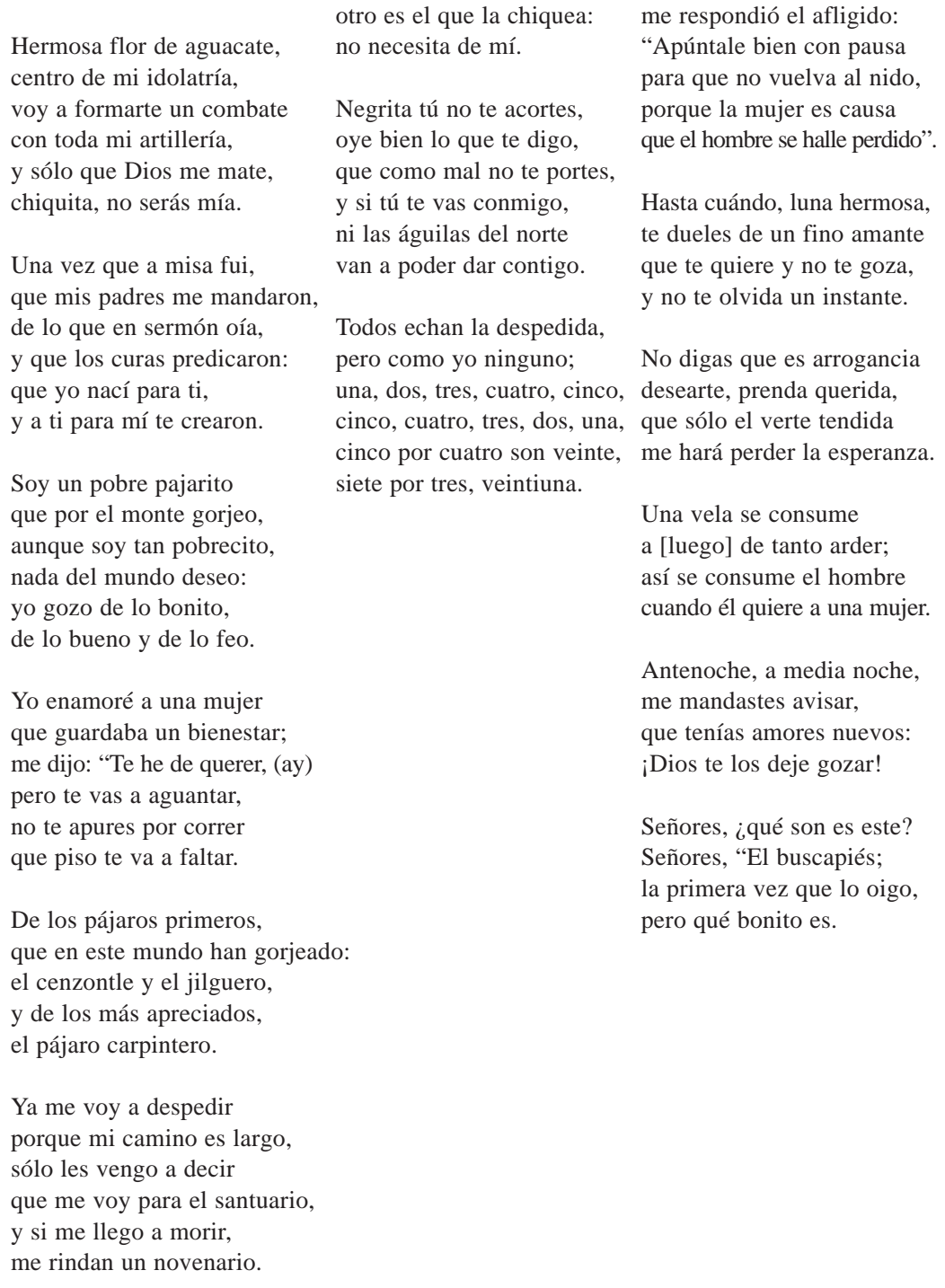

Además, hay que considerar que en un buen número de sones, el repertorio poético del cual echan mano los trovadores puede perfectamente rebasar el centenar de coplas.

En este tipo de series, las coplas, por su mismo carácter autónomo, tienden a no guardar entre sí relación alguna ni de in- 
dole formal ni de orden temático. La siguiente versión del Pajarillo jilguero de la Costa Chica es un buen ejemplo de una serie donde no existe unidad temática en lo absoluto:

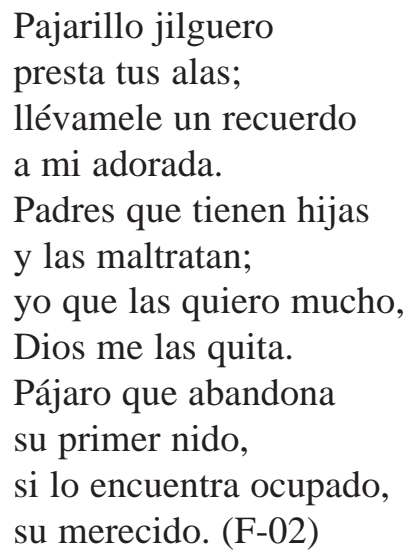

Estas series pueden, además, combinar estrofas de diferente número de versos (cuartetas, quintillas, sextillas e incluso décimas) como se puede observar en las interpretaciones realizadas por don Julián Cruz y el grupo Mono Blanco de El buscapiés, en el cuadro anterior. Y no sólo eso, existen casos de series que incluso llegan a mezclar coplas de diferente metro (cuartetas octosilábicas y seguidillas simples, por ejemplo). Estamos, pues, frente a un género lírico heteroestrófico, siguiendo la terminología de Margit Frenk, cuyo uso se remonta hacia el año de 1595 cuando el género de las seguidillas semipopulares surge como un estallido en España: "éstas se cantan en series más o menos largas, en que se suceden una a la otra sin necesaria conexión temática o expresiva" $(1978,260)$.

En estas mismas tres series de El buscapiés se puede observar otra característica de la estructura poética de los sones: el número de coplas que integran las distintas series que se cantan en un ejemplo musical determinado también varía de una interpretación a otra. Según la ocasión, el lugar, el número de 
participantes y otros elementos, la interpretación de un son puede constar de tres, cuatro o cinco coplas, o bien llegar a incluir entre 20 o 30. A esto se refería Jas Reuter al hablar de la longitud variable del son: aunque "la estructura es siempre la misma [...] no hay norma que establezca el número de coplas que deben intervenir en [la interpretación de] un son junto con sus correspondientes interludios para zapatear" (1981, 161). Es importante añadir que, de la misma manera, tampoco existe norma que establezca el número total de coplas que pueden ser cantadas en cada son, porque, en principio, el repertorio poético puede crecer libremente con la creación de nuevas coplas o la adaptación de otras. ${ }^{4}$

Pero la complejidad lírica de los sones va más allá aún. El carácter autónomo típico de las coplas no sólo se da a nivel de la relación que se establece entre ellas en una serie dada. $\mathrm{Mu}-$ chas veces esa independencia también se da respecto a la música misma, es decir, que una determinada copla mexicana puede ser cantada en distintos sones, incluso de diferentes regiones, y aun, puede aparecer en el canto de géneros populares de otros países. Tal es el caso de la siguiente seguidilla que aparece, con variantes, en los cancioneros folclóricos de España, Argentina y México:

$$
\begin{aligned}
& \text { No te cases con viejo } \\
& \text { por la moneda: } \\
& \text { la moneda se acaba } \\
& \text { y el viejo queda. } \\
& \text { (Magis 1969, 46-47) }
\end{aligned}
$$

Es curioso observar que en ese afán de adaptar algunas coplas populares a diferentes melodías se realicen con frecuen-

\footnotetext{
${ }^{4}$ Para dar una idea de la cantidad de coplas que pueden llegar a ser cantadas en un son determinado, la que escribe logró registrar 143 coplas de El cielito lindo, 142 de El gusto y 62 de El huerfanito, sones huastecos de los cuales se llegaron a escuchar un promedio de 40 versiones diferentes.
} 
cia variaciones importantes como añadir o sustraer algunos versos de la copla original, como sucede en dos versiones de $E l$ cielito lindo huasteco, donde el ejemplo anterior aparece con un estribillo para adaptarse a la estrofa característica de este son en la región huasteca: la seguidilla compuesta:

$$
\begin{aligned}
& \text { No te cases con viejo } \\
& \text { por la moneda, } \\
& \text { la moneda se acaba } \\
& \text { y el viejo queda; } \\
& \text { más te conviene } \\
& \text { casarte con un joven } \\
& \text { y lo mantienes. } \\
& \text { (F-04 y F-05) }
\end{aligned}
$$

Todos los rasgos literarios que han sido enunciados hasta aquí son los que me han llevado a calificar al son como un género de estructura lírica abierta, en oposición a otros géneros populares como el corrido, la valona y la canción, en los cuales la unidad lírica equivale al total de las estrofas componentes. Lo anterior determina que el conjunto poético global no admita por principio ni la inclusión de estrofas extras ni la omisión de alguna de las ya existentes. A éstos resulta más acertado denominarlos géneros líricos de estructura lírica limitada. No obstante, en la práctica, es común observar ciertas diferencias entre una interpretación y otra de una valona, una canción o un corrido determinado (cambios en el orden de las estrofas, sustitución de ciertas palabras por otras e, incluso, la ausencia de alguna estrofa o la presencia de una nueva). Estas modificaciones deben ser consideradas como "variantes" que se dan a nivel de la interpretación, características de la transmisión oral, y no como un rasgo estructural, como sucede en los sones. Un elemento importante que se deriva de todas las diferencias entre la poesía de los sones y la que se canta en este otro tipo de géneros es el hecho de que mientras en estos 
últimos el discurso literario guarda una correspondencia recíproca con el discurso musical, las series de coplas cantadas en los sones no guardan esa misma correspondencia, es decir que, en principio, a una música dada no le corresponde una letra determinada (Sánchez García 2003). ${ }^{5}$

Esta característica estructural de los sones ha sido detectada y expresada por pocos autores. Thomas Stanford, por ejemplo, sobre este asunto nos dice:

se debe afirmar - y esto es un hecho importante- que al parecer la mayoría de los sones mexicanos no tienen textos fijos, no se les puede identificar siquiera por ese aspecto con un nombre específico: hay simplemente un repertorio de melodías y un repertorio de coplas, y los músicos las juntan a su antojo. $(1984,22)^{6}$

Al respecto, Margit Frenk, hace ya cerca de tres décadas, afirmaba que la gran mayoría de las canciones no narrativas de los diferentes países de habla hispánica están compuestas de estrofas que se asocian muchas veces al azar y suelen cantarse con melodías de canciones distintas (1975-1985, 1-xvii). Fernández Arámburu, por su parte, llegó a manifestar con respecto a los sones huastecos que

no es posible hacer una clasificación exacta de los versos, debido a que en la región huasteca hidalguense es costumbre establecida que los cantadores usan versos de su repertorio sin considerar o tener en cuenta el nombre del huapango que se toca y solamente se guían por su melodía. (1955, nota de la p. 78$)^{7}$

\footnotetext{
${ }^{5}$ Esta idea ha sido ya expresada en mi artículo "Los sones y sus coplas: una propuesta para su estudio".

${ }^{6}$ Esto, nuevamente, es una generalización que, como se verá más adelante, no puede aplicarse por igual a las diferentes regiones donde se cultiva el son. Dicho en estos términos, se trata de una característica propia de un gran número de sones jarochos y, sobre todo, huastecos, mientras que en la región planeca de Michoacán, curiosamente la más estudiada por el investigador, resulta no ser tan frecuente.

${ }^{7}$ Dentro del término de 'canciones' la autora incluye a los sones.
} 
A partir de las anteriores podemos decir que es un material lírico, en principio ilimitado, de coplas que van y vienen de una interpretación a otra, de un son a otro y, en ciertos casos, de una región a otra. Esta característica particular, y a la vez de gran complejidad, muy posiblemente esté relacionada con los criterios utilizados en la recopilación de la lírica tanto de los sones, adoptados por el folclore — después retomados por la musicología-, como de los seguidos por la filología como se verá enseguida.

La recopilación y organización de las coplas: entre el folclore y la filología

Los criterios empleados en la labor de recopilación de los textos son rasgos fundamentales del estudio de la lírica. Sin entrar en detalles, en México existen dos grandes posturas que difieren tanto en los objetivos como en los métodos empleados. Por supuesto, sobra decir, en ambas corrientes existen aciertos y carencias. ${ }^{8}$

Por un lado, tenemos los trabajos realizados desde comienzos del siglo xx por los estudiosos del folclore, para quienes, en términos generales, al igual que para los musicólogos de unas décadas más tarde, ha sido importante observar el fenómeno literario dentro del contexto musical. Sin embargo, dentro de esta corriente, no se ha elaborado una verdadera recopilación - mucho menos un estudio — de la lírica de los sones. En general la ausencia de una metodología se advierte en hechos que van desde no proporcionar de manera sistemática el título del ejemplo musical del cual fueron extraídas las coplas que presentan - a veces tampoco el nombre de las fuentes o los lugares en que fueron recogidas_-, ${ }^{9}$ hasta la modificación

\footnotetext{
${ }^{8}$ Este ejercicio comparativo entre las dos corrientes de estudio fue esbozado en mi artículo "Los sones y sus coplas...”, Sánchez García 2003, 263-266.

9 Entre los autores que incurrieron en esto se encuentra el maestro Higinio
} 
textual realizada por algún investigador con la idea de mejorar la poesía, pues, el pueblo "carente de gusto estético y oído rítmico", al transmitirla de generación en generación la ha venido deformando y acaba por despojarla de sus virtudes originales (Campos 1991, 7 y 110).

En trabajos de recopilación más recientes se observa un problema diferente: la cantidad limitada de interpretaciones que han sido recogidas de cada uno de los diferentes ejemplos musicales resulta insuficiente para poder llevar a cabo un estudio apropiado sobre la relación que las coplas establecen con la música. ${ }^{10}$ Por otro lado, estas antologías están enfocadas a variantes regionales específicas sin considerar las similitudes y diferencias que se manifiestan entre todas ellas. ${ }^{11}$

Por su parte, tenemos los aportes que los filólogos han hecho en torno a la lírica popular de nuestro país, y dentro de esta corriente sobresale el Cancionero folklórico de México, publicado entre 1975 y 1985 bajo la coordinación de Margit Frenk, cuyo enfoque difiere de los trabajos de folcloristas y musicólogos, entre otras cosas, por la tendencia generalizada de extraer la letra del contexto musical. Siendo el aspecto literario el objeto de sus estudios, la unidad poética, en términos

Vázquez Santana (1931), cuyas recopilaciones, a pesar de haber sido una de las fuentes más valiosas en estudios posteriores, no han podido ser aprovechadas cabalmente por esta situación. Este problema también está presente, entre otros, en: Francisco Quevedo (1980), Hilario Meníndez (1925), José y Germán Fernández Arámburu (1955), Celedonio Serrano Martínez (1972) y en Cancionero michoacano (2000) de Álvaro Ochoa Serrano y Herón Pérez Martínez (ver bibliografía). Dicha situación puede deberse a un desinterés en el estudio de las coplas en relación con las melodías con las que se cantan, pero también existen casos en los que estas omisiones se deben a que las fuentes primarias de donde fueron tomados los ejemplos no especifican los nombres de los sones.

10 Véanse, por ejemplo, los trabajos de Thomas Stanford, sobre los sones de Tierra Caliente de Michoacán (1963); Humberto Aguirre Tinoco acerca de los sones jarochos (1983), y Manuel Álvarez Boada (1985), Raúl Guerrero Guerrero (1990) y René Villanueva (1997) sobre los huapangos de la Huasteca, los cuales consideran entre una y tres versiones por cada son.

11 Otro problema metodológico es la falta de un sistema único para presentar las coplas: en unas se considera la estructura original de la estrofa, en otras se atiende a la forma que resulta de la interpretación musical con repetición de ver- 
prácticos, debe ser reducida a la copla misma. Así tenemos que, según sea el contenido, existen coplas amorosas, coplas a la tierra, coplas que aluden a la muerte, coplas que nos hablan de la música y del baile, etc., o bien, según el tono, coplas humorísticas, serias, picarescas, sentenciosas y muchas más. ${ }^{12}$ En fin, se trata de una excelente antología de coplas organizadas a partir de un método riguroso en el que prevalece el aspecto temático. Este procedimiento, sin embargo - especialmente tratándose de un trabajo que abarca las diversas expresiones líricas de todo el país - tampoco resulta de gran ayuda para el estudio de la relación que se establece entre la música y la poesía o, mejor dicho, entre los sones de México y sus coplas. ${ }^{13}$

En esta revisión no pueden omitirse los estudios que el maestro Vicente T. Mendoza realizó sobre la lírica de México, y que por sus características pueden ubicarse entre los dos enfoques ya señalados. En cuanto a la cantidad de ejemplos reunidos y la utilización de una metodología en la recolección y ordenación de los materiales, su trabajo se acerca al realizado por la filología, pero difiere de esta disciplina, debido a que la letra y la música aparecen siempre como dos elementos co-dependientes e inseparables. Mendoza, sin duda, conocía bien el género que aquí nos ocupa, tal y como lo demuestran varios de sus escritos en los que hace referencia a la copla, por un lado, y a los sones, por el otro. ${ }^{14}$ Sin embargo, a nivel de géne-

sos y cambio de orden de los mismos, y en otras más se utilizan las dos maneras indistintamente.

${ }^{12} \mathrm{Si}$ bien la clasificación temática de coplas es un asunto en el que se ha trabajado desde hace mucho tiempo, en México, queda por hacerse un estudio acerca de los temas en relación con los sones mismos, lo que nos llevaría a conocer más sobre el carácter monotemático o politemático de los sones, así como de los diversos motivos que aparecen en las diversas variantes regionales.

${ }^{13}$ A pesar de la separación de los textos respecto al discurso musical que se observa en el Cancionero, el rigor metodológico aplicado en esta obra sí considera siempre el nombre de las fuentes y el título del ejemplo musical. Cuando esto no ha sido posible, por no existir en la fuente el título del ejemplo musical específico, se consigna simplemente como "copla suelta".

${ }^{14}$ Habla sobre el son y las coplas en distintas publicaciones, principalmente en el capítulo III de El Panorama de la música tradicional mexicana y en el ar- 
ros musicales su interés se centró en aquellos que aquí he llamado "de estructura lírica limitada", de los cuales el autor nos dejó una cuantiosa recopilación de ejemplos, que organizó y clasificó a partir de diferentes parámetros, siendo el aspecto temático el predominante.

Una recopilación más a fondo de las coplas cantadas en los sones, así como su posterior estudio con relación a su contexto musical es lo que sigue haciendo falta dentro del campo de la lírica popular mexicana.

¿Se debe, acaso, al carácter politemático que existe en un gran número de sones y a la no correspondencia unívoca entre música y letra lo que ha impedido llevar a cabo un acercamiento similar al realizado con otros géneros?

Lo primero que habría que cuestionarse es si la aludida separación entre el discurso musical y el poético es una constante en este género, es decir, si la elección de coplas es completamente aleatoria en todos y cada uno de los diferentes ejemplos musicales. ¿No será posible que existan algunos (o varios) sones en los que sí se establece una relación, si no recíproca, sí determinada por ciertos códigos de significación entre música y letra? En mi opinión, son varios los puntos de avenencia que, en menor o mayor grado, se dan en la relación que se establece entre estos dos aspectos, y lo que se intenta en estas páginas es mostrar que así como hay diferentes tipos de canciones,

tículo "La copla musical en México" (1945). Es importante hacer notar que el conocimiento que el maestro Vicente T. Mendoza tuvo acerca de los diferentes géneros cantados en nuestro país fue evolucionando con el paso del tiempo, y aunque en general no hace la distinción entre coplas y estrofas como aquí lo hemos hecho, y llega incluso a decir que "muchas canciones, corridos, sones, huapangos, bolas, gustos o sandungas mexicanas, observadas en su estructura literaria no son sino series de coplas, es decir, estrofas breves que encierran un pensamiento completo y bien definido" $(1945,189)$, sabemos, a través de escritos posteriores, que llegó a tener una clara noción de la diferencia entre los géneros mencionados. Véanse, por ejemplo, sus reflexiones sobre la imposibilidad de confundir los corridos y los romances con las canciones $(1982,28)$, o la diferenciación que establece entre la canción de metro octosílabo y los géneros líricos compuestos por coplas, en su mayoría también de ocho sílabas $(1982,43)$. 
valonas o corridos, también hay diferentes tipos de sones, y éstos, además, no se presentan en todas las variantes regionales, o al menos no con la misma frecuencia.

\section{Las variantes regionales}

En el estudio general de los sones, un primer paso sería dar una mayor importancia al hecho de que entre las distintas expresiones regionales del son existen diferencias que, sin duda, nos hablan de influencias de diferente origen y de desarrollos musicales particulares en los que se ven reflejados modos de percepción, pensamiento y expresión específicos, con los cuales los pobladores de las diversas zonas se identifican plenamente.

Vicente T. Mendoza acertadamente hizo hincapié en el hecho de que en la creación del son intervinieron numerosos ritmos musicales, bailes teatrales y géneros líricos de diferente tipo introducidos a nuestro país a lo largo de los siglos XVII y XVIII (1984, 65 y 87-88). No sólo eso, las diversas regiones donde se manifiesta el son han recibido con el paso del tiempo influencias muy variadas; así la llegada de marineras y cuecas sudamericanas por las costas del sur del Pacífico, o las influencias musicales venezolana y cubana por el lado del Golfo. El resultado de la combinación de tantos géneros y estilos distintos se ve reflejado, sin duda, en cada una de las manifestaciones regionales del son en México, y aun en cada zona, los materiales no son homogéneos. Un ejemplo de estas diferencias regionales se manifiesta de manera muy evidente entre el son huasteco y el son jarocho, entre los que, a pesar de su cercanía geográfica, se observan pocas semejanzas en comparación con las existentes entre este último y los sones de la región sud-occidental del país. ${ }^{15}$

15 Véase Sánchez García 2002, 121-152. 
La visión generalizadora que encontramos dentro de los trabajos de folcloristas y musicólogos también se observa en algunos estudios realizados dentro del campo de la literatura. Así, por ejemplo, el ensayo de Martín Sánchez Camargo (2002), en el que, a pesar de que propone ver a la copla como un reflejo del ámbito sociocultural donde se genera y, en esos términos, entender que los recursos estilísticos utilizados en ella funcionan de acuerdo a formas de configuración del mundo de grupos culturales y sociales específicos, los ejemplos que emplea para su argumentación no reflejan la realidad lírica de las coplas mexicanas.

Es el estudio de las diferencias regionales a partir de una orientación comparativa lo que nos permitirá, en mi opinión, conocer mejor uno de los géneros líricos más complejos de nuestra cultura musical popular; esto, si es verdad que se puede decir que se trata de un solo género musical.

En el aspecto literario podemos, en un primer nivel de análisis comparativo, señalar cinco rasgos que se manifiestan de diferente manera en los sones de las diversas regiones:

1) Las estrofas. De manera general, se dice que la lírica popular hispánica contemporánea se manifiesta en dos formas fundamentales: la cuarteta octosilábica romanceada y la seguidilla simple. En nuestro país, esto se da de una manera casi textual en algunas zonas de la región del Pacífico: en los sones de arpa grande de Michoacán y los jaliscienses o sones de mariachi. En la región de Veracruz, las dos formas están presentes en un gran número de sones jarochos, aunque las cuartetas aparecen casi siempre en combinación con estrofas de diferente número de versos, especialmente las sextillas; algo similar sucede en los sones calentanos, sólo que ahí las sextillas son las que prevalecen. En los sones de la Huasteca, en cambio, a excepción de unos pocos sones paralelísticos que veremos más adelante, la cuarteta está ausente por completo, y en su lugar aparece de manera notoria la quintilla, que con- 
vive de manera muy cercana con la sextilla. Este gusto peculiar de los huastecos por la quintilla ha provocado que a ciertas coplas que eran originalmente cuartetas se les haya añadido un quinto verso. Por el contrario, este tipo de estrofa es prácticamente desconocida en los sones del Pacífico. ${ }^{16}$ La seguidilla, muy presente en todas las variantes regionales, en la Huasteca tiene la singularidad de aparecer siempre con estribillo. Finalmente, los sones jarochos son los únicos que incluyen en su repertorio décimas que consideran también como coplas y se combinan con otras estrofas.

2) La estructura literario-musical. Las series de coplas independientes que alternan con puentes musicales, aunque presentes en todas las variantes regionales, no constituyen en todas ellas — como se había creído- la estructura más generalizada, a excepción del son de la Huasteca donde esta forma es prácticamente la única. La forma que combina estrofa y estribillo, sea del tipo que sea, es muy común, si no predominante, tanto en los sones de Occidente como en los sones jarochos.

3) El metro. Las series de coplas sueltas en el son huasteco son siempre de metro octosílabo. En el resto de las variantes, debido en gran medida al uso del estribillo, existen, además, coplas de metros diferentes como el hexasílabo, el heptasílabo, el pentasílabo y, más excepcionalmente, otros de arte mayor como el decasílabo y el dodecasílabo. En consecuencia, en la región de Occidente y en el estado de Veracruz, son muy frecuentes los sones cuyas series combinan estrofas de diferente medida, como la siguiente versión de La Cirila de Tixtla, Guerrero, cuyas coplas son seguidillas simples y sus estribillos son cuartetas pentasilábicas:

16 "En otras regiones se encuentran coplas de cinco versos, que no he encontrado en la costa de Michoacán" (Stanford 1963, 233). "Aunque esta forma estrófica [la quintilla] no es tan común en Guerrero, suelen encontrarse, sin embargo, algunas muestras de ella. [...] Conviene aclarar aquí, que este tipo estrófico, es el que predomina en los sones y huapangos que se cantan en las tres huastecas" (Serrano 1972, 73). 

Copla: De todos los colores me gusta el verde porque las esperanzas nunca se pierden.
Estribillo: Te vas Cirila, te vas, te vas, te vas conmigo a Panamá. (F-06)

Por otro lado, en el son jarocho, lo mismo que en el son planeco y el jalisciense llegan a encontrarse con frecuencia coplas de versificación irregular, es decir, que combinan versos con diferencias de medida notables entre sí, que no aparecen en absoluto en la Huasteca:

Las arenitas, Jalisco y Michoacán: coplas = cuartetas (8-58-5) y sextillas (8-5-5-8-5-5)

Las Campanitas, Jalisco: estribillos = cuartetas (4-8-8-8)

La guacamaya, Veracruz: estribillos = cuartetas (6-6-8-8)

El cupido, Veracruz: estribillos $=(10-10-10-8)$

4) El canto de las coplas. Dos voces son las que intervienen, por lo general, en el canto de las coplas. Sin embargo, mientras que en los sones de la Huasteca y los sones jarochos éste se da de manera responsorial, en las variantes regionales de Guerrero, Michoacán y Jalisco predomina el canto simultáneo.

5) Las formas interpretativas de las estrofas. Las formas que resultan del canto de las coplas son sumamente variadas, y las diferencias se manifiestan incluso de un son a otro en una misma región. Lo único que puede observarse como rasgo regional es que, en el canto alterno de los sones de la región oriental, la constitución de cuatro cuartetas, por medio de la repetición de algunos versos, es la forma más frecuente en los sones jarochos, mientras que en los huastecos es la de tres cuartetas. 


\section{La diferencia entre coplas libres y coplas exclusivas}

Como ya se dijo, sí es posible, e incluso deseable, realizar un estudio que logre reconciliar el universo musical y el universo poético de los sones en México, a pesar de que, a primera vista, parecería que ambos discursos siguen caminos independientes, y cuya relación se muestra más bien casual.

El principio más general nos dice que un rasgo típico de las coplas es el de poder cantarse con diferentes melodías. Esto, sin lugar a dudas, es cierto, pero, ¿sucede así con todas las coplas y en todos los sones? Entre los propios músicos populares existe la idea de que "cualquier copla puede cantarse en cualquier son", palabras que llegué a escuchar en voz de algunos huapangueros de la Huasteca. Sin embargo, mis estudios me han llevado a reconocer la existencia de dos tipos de coplas diferentes: las que pueden ser cantadas en distintos sones y las que sólo se cantan en uno específico; a las primeras las he denominado "libres" y las segundas reciben el nombre de "exclusivas". Además, queda claro que "la diferenciación entre unas y otras no es simple obra de la casualidad, sino que responde a criterios específicos de selección por parte de los trovadores, quienes, probablemente de manera inconsciente, saben qué coplas caben en varios sones y cuáles son destinadas a uno exclusivamente" (Sánchez García 2003, $267-$ 268).

Como lo expliqué entonces, para lograr reconocer la diferencia entre estos dos tipos de coplas es preciso considerar, de manera conjunta, tres elementos: primero, la presencia o ausencia de una palabra clave que sirve para establecer un vínculo entre ciertas coplas y un son específico, y que en muchas ocasiones les otorga el carácter de exclusividad; segundo, la estructura formal de las estrofas que conforman las diferentes series, y tercero, el carácter monotemático o politemático de los diferentes sones (Sánchez García 2003, 62). 
La palabra clave equivale al título mismo del son, o está en estrecha relación con éste. Así tenemos que las palabras "llorar", "aguanieve", "rosa" y "caballito" o "caballo", etc., aparecen en coplas destinadas a ser cantadas en los sones que llevan por título esos mismos nombres, en este caso, huapangos huastecos; lo mismo sucede en otras regiones, por ejemplo, para los sones jaliscienses El borracho, El cihualteco y El capulinero, las palabras clave son "borracho", "Cihuatlán" o "cihualtecas" y "capulinero" o "capulines", respectivamente.

Un gran número de este tipo de coplas, quedan, por decirlo de alguna manera, "selladas" por esta palabra clave, la cual funciona como un candado que las limita al contexto musical de un son específico. No obstante, al examinar las coplas de este tipo hay que tener en cuenta un fenómeno que sucede con frecuencia. La fuerte tendencia de las coplas por mantener su libertad y poder ser cantadas en diferentes sones provoca que en ciertos casos la palabra clave sea cambiada por otra para que la copla pueda, de esta manera, ajustarse a otros contextos musicales. La siguiente copla huasteca que aparece con mayor frecuencia en el son La rosa,

Rosita, si tú supieras las penas que por ti paso, y de mí te condolieras y me dieras un abrazo, aunque amor no me tuvieras

transforma su palabra clave, "Rosita", por "Conchita" o "Cecilia" para cantarse en los sones que llevan por nombre Las conchitas o La Cecilia, e incluso, por "morena" para adaptarse al huapango de El bejuquito. Esto también sucede de una región musical a otra; por ejemplo, la siguiente copla que hace un intercambio entre los vocablos "frijolito" y "bejuquito" para poder ser cantado tanto en El frijolito jalisciense como en El bejuquito huasteco: 
Frijolito, frijolito, (Bejuquito, bejuquito)

frijolito enredador, (bejuquito...)

no te vayas a enredar

como se enredó mi amor. ${ }^{17}$

La estructura formal de las estrofas también es importante a la hora de determinar la exclusividad de algunas de ellas, ya que existen algunos sones que se componen de coplas con una estructura que es única dentro del repertorio de la región; por ejemplo, el son planeco Las arenitas, también conocido como Arenita de oro en Jalisco, que incluye cuartetas y sextillas irregulares (8-5-8-5 y 8-5-5-8-5-5), las cuales no aparecen en otros sones y que por tanto no puede compartir sus coplas. El paralelismo es otro recurso literario que puede otorgar el carácter exclusivo a las coplas de ciertos sones. Los ejemplos musicales con estas características formales son un tipo de son que se acerca más a la forma canción.

Finalmente, el carácter monotemático o politemático de los diferentes sones debe a su vez ser considerado, ya que puede suceder que cierto tema sólo aparezca en un son particular, y por ese motivo sus coplas sólo se cantarán en ese son, tal y como sucede con los sones llamados ambos El borracho, uno de la Huasteca y otro del repertorio de mariachi.

\section{Hacia una clasificación del son mexicano}

Si bien queda claro que no se puede elaborar una tipología precisa de los diferentes tipos que existen de son, al menos no a la manera utilizada en otros géneros líricos, sí es posible formar grupos a partir de características que sólo comparte un cierto número de sones. Del mismo modo que sucede en la

17 En el caso del son huasteco, debido a que las cuartetas no son parte de su repertorio, a esta copla se le añade un quinto verso: "cuando estaba muy solito". 
clasificación de las coplas, esto se puede hacer a partir de diferentes parámetros: el o los temas cantados, el tono, las formas estróficas, la estructura literario-musical, el uso de coplas libres o exclusivas, las formas de interpretación, según el nivel de asociación entre las coplas, etc. Si tomamos como criterio, por ejemplo, los temas cantados en los sones, observamos, en primer lugar una distinción entre sones monotemáticos y sones politemáticos, y en un segundo nivel, tendríamos, por un lado, los sones amorosos, de animales, de vaquería y otros sones dirigidos a temas específicos, y por el otro lado, quedarían los sones de temática limitada y los sones de temática ilimitada. Si en lugar del criterio temático consideramos las formas estróficas utilizadas, una primera distinción se establecería entre los sones de series de coplas homogéneas (compuestas por sólo un tipo de estrofa) y los sones de series heterogéneas (que incluyen estrofas diferentes). O si partimos de la estructura literario-musical, los sones se dividirían entre los que no tienen estribillo y los que sí lo llevan, y dentro de estos últimos, encontraríamos que hay unos cuyo estribillo se conforma de una frase del tipo "ay, la, ra, lá", otros que elaboran el estribillo a partir de la copla que le precede, y otros más en los que el estribillo es una estrofa completamente diferente a la copla, la que, además, puede variar o no. Y así, podríamos continuar.

Ahora bien, si elaboramos una tipología de los sones a partir del uso de las coplas libres y exclusivas, explicadas anteriormente, se puede obtener una clasificación más general que, al abarcar varios de los aspectos mencionados, nos proporciona un panorama más completo de los diferentes tipos de sones que existen.

La primera gran división consistiría en reunir en un grupo a los sones que sólo utilizan coplas exclusivas, y en otro, a los sones cuya lírica incluye, además, coplas libres. Al interior de cada uno de estos dos grandes grupos, a su vez, es posible establecer algunas sub-categorías: 
I. Sones compuestos por coplas exclusivas

I.1 Sones paralelísticos

a. sin estribillo (La acamaya de la Huasteca, El becerrero de Michoacán y Jalisco)

b. con estribillo (El carretero de Jalisco, El camotal de la Huasteca, La gallina en Michoacán y la Huasteca)

I. 2 Sones con formas estróficas únicas en un repertorio particular (Las arenitas en Michoacán y Jalisco, La araña en la Huasteca)

I.3 Sones monotemáticos de tema exclusivo en el repertorio regional

a. sin estribillo (El dos de Michoacán, El gavilancillo de Michoacán y Jalisco)

b. con estribillo (El canelo de Veracruz)

I.4 Sones cuya temática gravita alrededor de una palabra clave en todas o la mayoría de sus coplas

a. sin estribillo (El caballito, El querreque de la Huasteca, El cihualteco, Las campanitas de Jalisco)

b. con estribillo (Las abajeñas de Jalisco y Michoacán, La tortolita de Guerrero y Michoacán).

I.5 Sones-canción con coplas fijas que aparecen en todas las versiones y casi siempre en el mismo orden

a. sin estribillo (Camino real de Colima de Jalisco)

b. con estribillo (El cuervo de Jalisco, El toro rabón de Tixtla, Guerrero)

II. Sones compuestos por coplas libres y exclusivas

II.1 Sones monotemáticos, cuyo tema se canta también en otros sones del repertorio y por tanto puede compartir coplas (El apasionado, El campechano, La llorona y El sentimiento de la Huasteca).

II. 2 Sones politemáticos limitados que cantan de dos a tres temas diferentes.

II. 3 Sones politemáticos ilimitados que incluyen todos, o la mayoría, de los temas que se acostumbran en el repertorio de cada variante regional: el amor feliz, la pasión, la tristeza, la orfandad, coplas a la tierra, sobre la música y el baile, a la madre, de saludo y despedida, las que aluden a diferentes labores del campo, etc. 
Por último, si se hiciera un examen comparativo entre las seis principales variantes regionales del son, considerando todos los tipos presentados en el cuadro anterior, se obtendría un panorama completamente heterogéneo. Por dar sólo una idea: el grupo más representativo y numeroso de sones en la región huasteca está representado por aquellos que por su carácter politemático tienen un acervo de coplas muy amplio (hasta más de cien) y un gran número de ellas son coplas libres que comparten con muchos otros sones. Este tipo de sones, aunque de manera más reducida, también se encuentra entre los sones jarochos; por el contrario, en los sones de las variantes ubicadas en Guerrero, Michoacán y Jalisco, éstos son más bien excepcionales. Por otro lado, los sones paralelísticos, comunes a todas las variantes del son del Occidente de México y de Veracruz, aparecen casi como una curiosidad entre los sones de la Huasteca, los que, además, sólo se cantan en ciertas sub-regiones.

Como puede observarse, desde esta óptica, es mucho lo que queda por estudiarse y decir acerca de la lírica del son; y algo similar sucede respecto a los otros dos elementos que lo constituyen: la música y el baile. Lo escrito aquí es ante todo una invitación a retomar el tema del son como uno de los principales campos de estudio dentro del panorama de la música popular de México. Por el lado de la filología, los trabajos de investigación sobre los temas, los símbolos, la rima y otros elementos más, propios de las coplas, se siguen haciendo. Pero es claro que sus alcances implican un enfoque parcial al separar los textos del contexto musical. Es en esa relación entre la poesía y la música de los sones donde persiste un gran vacío en el estudio de la lírica en México, laguna que corresponde a los musicólogos llenar, y qué mejor si se hace con el auxilio de las herramientas metodológicas que la filología viene desarrollando desde hace varios años. 


\section{REFERENCIAS}

Aguirre Tinoco, Humberto, 1983. Sones de la tierra y cantares jarochos, México, Premia editora.

Álvarez BoAda, Manuel, 1985. La música popular en la huasteca veracruzana, México, Premia.

CAmpos, Rubén M., 1991 [1928]. El folklore y al música mexicana. Investigación acerca de la cultura musical en México (15251925), México, Publicaciones de la Secretaría de Educación Pública, CENIDIM, INBA, reproducción facsimilar.

Díaz Roig, Mercedes, 1976. El romancero y la lírica popular moderna, México, El Colegio de México.

Fernández Arámburu, José y Germán, 1955. "Versos de huapango", Anuario de la Sociedad Folklórica de México, 71-78.

Frenk, Margit (coord.), 1975-85, Cancionero folklórico de México, México, El Colegio de México, 5 vols.

—, 1978. Estudios sobre lírica antigua, Madrid, Castalia.

GUERRERo Guerrero, Raúl, 1990. Un recorrido por la Huasteca hidalguense, México, INAH (Colección Divulgación).

Magis, Carlos H., 1969. La lírica popular contemporánea, EspañaMéxico-Argentina, México, El Colegio de México.

Mendoza, Vicente T., 1945. "La copla musical en México", Аnиario de la Sociedad Folklórica de México, 189-202.

—,1984 [1956]. Panorama de la música tradicional de México, México, Dirección General de Publicaciones de la Universidad Nacional Autónoma de México.

-,1982. La canción mexicana. Ensayo de clasificación y antología [1961], México, UNAM, $2^{\mathrm{a}}$ ed.

Meníndez Peña, Hilario, 1925. Cantares huastecos o versos de huapango, México, [s. ed.].

Ochoa Serrano, Álvaro y Herón Pérez Martínez, 2000. Cancionero michoacano 1830-1940, Zamora, El Colegio de Michoacán.

Quevedo, Francisco, 1980. Lírica popular tabasqueña [1916], Tabasco, Consejo Editorial del Gobierno del Estado de Tabasco.

Reuter, Jas, 1981. La música popular de México, México, Panorama.

SÁNChez CAmargo, Martín, 2002. "Recursos estilísticos en la copla popular mexicana”, Revista de Literaturas Populares 2-2, 109-138. 
SÁnchez García, Rosa Virginia, 2002. "Diferencias formales entre la lírica de los sones huastecos y la de los sones jarochos", $R e$ vista de Literaturas Populares 2-1, 121-152.

—, 2003. "Los sones y sus coplas: una propuesta para su estudio", en El folclor literario en México, Zamora, Michoacán, El Colegio de Michoacán-Universidad Autónoma de Aguascalientes, pp. 261272.

Serrano Martínez, Celedonio, 1972. Coplas populares de Guerrero, México, Libros de México.

STANFORD, Thomas, 1963. "La lírica popular de la costa michoacana", Anales del Instituto Nacional de Antropología e Historia 16 (Sexta época, México, INAH), 231-282.

-,1984. El son mexicano, México, Fondo de Cultura Económica.

VÁzQuez S antana, Higinio, 1931. Historia de la canción mexicana, tomo III, México, Talleres gráficos de la Nación.

Villanueva, René, 1997. Cancionero de la Huasteca, México, IPN.

Fonografía

F-01. Julián Cruz. Jaranero. Casete. México, Pentagrama, 1996.

F-02. Antología del son de México. LP. $1^{\mathrm{a}}$ ed., México, FONARTFONAPAS, 1981. En CD, CORASON, 2002.

F-03. Mono blanco. Sones jarochos, vol. V. Casete. México, Pentagrama, 1996.

F-04. México: Música de la Huasteca [II]. Cinta de carrete abierto. México, D. F., enero de 1974 y agosto de 1973. Grabación de René Villanueva.

F-05. Encuentro de Huapango en Amatlán 96. Casete. Amatlán, Ver., noviembre de 1996. Grabación de Rosa Virginia Sánchez.

F-06. Sones de tarima de Tixtla, Gro. Grupo Fandanguero. Casete, [s.1.; s.n.], 1994. 